
\title{
Geopolymerization of Raw Fly Ash to Sodium Zeolites for Sequestration of As (III) in Aqueous Medium
}

\author{
Tabassum Hussain ${ }^{1}$, Shahzad Ali Shahid Chatha ${ }^{2}$, Muhammad Arshad ${ }^{3 *}$, Abdullah ljaz Hussain ${ }^{2}$, \\ Adnan $\mathrm{Ali}^{4}$ \\ 'Department of Applied Chemistry, Government College University, Faisalabad, Pakistan; \\ tabassumehussain@gmail.com \\ 2Department of Chemistry, Government College University, Faisalabad, Pakistan; chatha222@gmail.com, \\ abdullahijaz@gcuf.edu.pk \\ 3SST Science, Govt. Fazilka Islamia Model High School Pakpattan, Punjab, Pakistan; marshadzakki@gmail.com \\ 4Department of Physics, Government College University, Faisalabad, Pakistan; adnnan_1982@yahoo.com
}

\begin{abstract}
Objective: Massive quantity of Raw Fly Ash (RFA) is generated during incineration due to rapid surge in global energy needs posing severe threat to natural balance owing to constraints associated with its storage and disposal. There exists a pressing and ongoing need to recycle RFA into novel mesoporous geopolymer that can sanitize aqueous medium from hazardous As (III) posturing bioaccumulation. Methodology: NaOH activated Fusion based Hydrothermal Technique (FUHT) was applied for synthesis of sodium zeolites from cost effective Si and Al source i.e. RFA. The characteristics like morphology and surface porosity, surface chemistry and crystallinity in conjunction with ion exchangeability of the Geopolymerized Sodium Zeolite (GSZ) were evaluated by SEM, FTIR, XRD and CEC techniques, respectively. We investigated that scavenging performance of the adsorbent for sequestration of As (III) via ICP-AES and optimized at $\mathrm{pH} \approx 8$ for 30 minutes by using $150 \mathrm{mg}$ of adsorbent dose. Findings: Adsorption results confirmed that the developed sodium zeolite composites favor multilayer heterogeneous adsorption isotherm. Application: The effort towards industrial waste recycling into value added materials is an emergent move toward achieving a sustainable environment.
\end{abstract}

Keywords: Adsorbent Materials, As (III) Removal, Fly Ash, Water Treatment, Zeolite Synthesis

\section{Introduction}

Hazardous wastes are exhausted all over the world by industries and their discarding attitude poses foremost challenges and severe environmental issues. In recent times, fly ash waste and supplementary offshoot have been in the process of being constructively used in a number of applications. The green recycling of Raw Fly Ash (RFA) into Geopolymerized Sodium Zeolite (GSZ) equally contributes to the environmental remedy, generally in the field of solid waste management. There are vast challenges all over the world concerning the management of waste water for a sustainable environment. In various under developed countries, there are noxious consequences allied with exposure to polluted water, as they have rising population densities, increasingly scarce water resources and inadequate water treatment systems. Waste water treatment and management is the last line of defense designed for water pollution in the world. Conversely, carcinogenic and mutagenic nature of heavy metals like $\mathrm{As}, \mathrm{Hg}, \mathrm{Pb}$ and $\mathrm{Cd}$ are classified as a priority pollutant $\underline{1}$. These metals are renowned toxicants even at minor concentrations, which

${ }^{*}$ Author for correspondence 
affect organelles involved in detoxification, DNA repairing system and metabolism ${ }^{2,3}$. In a straight line, when these toxic metal ions are consumed through air, food or water, they pose severe threatens to the life and become detrimental when it gets accumulated in the soft body organ without metabolized in the body. Due to the swift extension of industrializations, heavy metals are frequently discharged and damaging aquatic environment $\frac{4-6}{-6}$. Amongst heavy metal ion series, inorganic arsenic is considered to be the most contaminating element because of its injurious effect even at little concentration.

Arsenic $\left[{ }^{74.92} \mathrm{As}=[\underline{\mathrm{Ar}}] 3 \mathrm{~d}^{10} 4 \mathrm{~s}^{2} 4 \mathrm{p}^{3}\right]$ is the $20^{\text {th }}$ most abundant element on earth crust and its ionic forms such as arsenite (III) and arsenate (V) compounds are lethal to the environment and living organisms. Arsenic (III) is 10-60 times more severe than As (V) and prolonged contact leads to tissue damage and organ failure ${ }^{7}$. In potable and natural water system, the toxicity of As (III) has been detected all over the world which leads to various diseases ${ }^{8,9}$. Therefore, World Health Organization (WHO) adopts the instruction of $10 \mathrm{ug} / \mathrm{L}$ as permissible limit ${ }^{10}$, hence, elimination of As (III) is very much crucial for the protection of both human health and the environment. As health hazard imposes immense demands on the humanity for the removal of noxious metals from the water bodies before any use $\mathrm{e}^{11-13}$. Henceforth, it is indispensable to ascertain a system that is actable for the removal of heavy metals like arsenic on waste site, which can be performed even by a lay man. Among diverse physical separation techniques ${ }^{14}$ ion-exchange sorbents considered to be the best for treating waste resources as selective and least expensive characteristics. The composite zeolites show superior physico-chemical character in terms of chemo-thermal stability and potential applications as gas absorbers, photo-catalytical bed $\frac{15}{15}$ ion selective adsorbents $\frac{16}{16}$ and chelating agents for exploration and sequestration of radioactive isotopes ${ }^{17}$. Majority of water managing technologists using zeolites for waste water purification, as these geopolymers based on exceptional cation-exchange performance, through which dissolved cations especially heavy metals can be removed from contaminated water. By and large, the preparation of zeolites is expensive, therefore, their applications in green remediation is constrained owed to excessive costs. Cost margins can be prevailing over by using economical materials for zeolite synthesis i.e. Raw Fly Ash RFA ${ }^{18}$. The exercise of these waste materials in the geopolymerization of zeolite is evaluated, probing their feasible application in the remediation of waste water ${ }^{19,20}$. Fly ash based zeo- lites are inorganic mesoporous crystalline geopolymers known for valuable applications, which are gaining new exploration interests predominantly due their characteristics properties like; ion exchangeability, catalysis and adsorption ${ }^{21}$. Yet, the main environmental applications of zeolites include sequestration of heavy metals from contaminated water concerning with pollution control $^{21}$.

The foremost pro of RFA based synthetic zeolite material is that, they can be engineered with a wide range of chemical properties, surface area, mesoporosity and thermal stability. They are known exceptional economical sorbents that can eagerly swap over lot of hazardous materials in their structural voids.

\section{Materials and Methods}

The geopolymerization of zeolite was carried out from Raw Fly Ash (RFA) that can be classified as cheap Si and $\mathrm{Al}$ source. RFA grab sample was procured as raw aluminosilicate source from Electrostatic Precipitator (ESP) of the boiler plants at Shabbir dyeing industry, Shadman road, Faisalabad, Pakistan. Hydrochloric acid ( $\mathrm{HCl} 37 \%$ Sigma Aldrich), sodium hydroxide ( $\mathrm{NaOH}, 99 \%$, Merck), sodium aluminate $\left(\mathrm{NaAlO}_{2}, 98 \%\right.$, Sigma Aldrich), sodium silicate $\left(\mathrm{Na}_{2} \mathrm{SiO}_{3} \cdot 9 \mathrm{H}_{2} \mathrm{O}, 99 \%\right.$, Merck $)$ and arsenic trioxide $\left(\mathrm{As}_{2} \mathrm{O}_{3}\right.$ 99\% Sigma Aldrich) were of analytical grade and used as received. Deionized water (DI. $\left.\mathrm{H}_{2} \mathrm{O}\right)$ for the preparation of the solutions and double distilled water (DD. $\mathrm{H}_{2} \mathrm{O}$ ) for washing of residues were used.

\subsection{Physico-chemical Properties of RFA}

Pretreatment of the RFA was carried out for the synthesis of sodium based aluminosillicates. Sample was powdered and sieved under dry conditions by using 80 mesh size sieve to eliminate coarser particles leaving fine ash particles ranging from $<150-200 \mu \mathrm{m}$ in diameter ${ }^{23}$. The $\mathrm{pH}$ was measured by using $0.5 \mathrm{~g}$ of the treated RFA in DI. $\mathrm{H}_{2} \mathrm{O}$ and stirred well for $24 \mathrm{~h}$ at $30^{\circ} \mathrm{C}$. After trembling and filtration, $\mathrm{pH}$ and $\mathrm{EC}$ measurement were evaluated $\mathrm{d}^{24}$. Loss on ignition of RFA was calculated by ASTM D-7348 procedure in order to check the un-burnt carbon contents in the RFA (ASTM D-7348, 2011).

\subsection{Alkaline Fusion followed by Hydrothermal Synthesis}

An alkaline fusion step was engaged proceeding to the hydrothermal treatment, because it plays a significant role in augmenting the hydrothermal process for zeolite blending. 
In a representative synthesis, $25 \mathrm{~g}$ of Raw Fly Ash (RFA) was dry mixed with $12.5 \mathrm{~g}$ of $\mathrm{NaOH}$ powder (2:1) for 30 minute in a blend mixer and the resultant mixture was fused at $550^{\circ} \mathrm{C}$ keeping in china dish using muffle furnace for two hours by adjusting the ramp rate. The resultant Fused Zeolite (FUZ) was ground in a mortar and stored after sieving for further characterization, syntheses and applications. Additionally, the resultant FUZ (12.5 g) was dissolved in $125 \mathrm{ml}$ Deionized Water (DiW) to form the amorphous precursors gel in double neck reactor under reflux conditions for hydrothermal treatment. For the adjustment of $\mathrm{Si} / \mathrm{Al}$, externally $\mathrm{NaAlO}_{2}$ and $\mathrm{Na}_{2} \mathrm{SiO}_{3} \cdot 9 \mathrm{H}_{2} \mathrm{O}$ solutions were mixed in polypropylene beakers and poured into the reaction vessel drop wise, keeping the solid to liquid ratio (0.1). The oil bath temperature was adjusted to $120^{\circ} \mathrm{C}$ resulting in the solution temperature of about $100^{\circ} \mathrm{C}$ under atmospheric pressure ${ }^{25}$. So, the resultant gel was refluxed at $100^{\circ} \mathrm{C}$ for $8 \mathrm{~h}$ with stirring. The resultant reactor was disengaged at the programmed time and quenched in ice cold water bath to stop the reaction. After decantation and centrifugation whole the gel was filtered and resultant supernatant was measured and stored in polypropylene bottle for further analysis. The $\mathrm{pH}$ and EC of the supernatant were measured by a multimeter water quality analyzer HI-9811-5 after dilution $(0.005 \mathrm{v} / \mathrm{v})$ mentioned in Table $1{ }^{26}$. The residue was washed with double distilled water $\left(\mathrm{DD}-\mathrm{H}_{2} \mathrm{O}\right)$ five times $(5 \mathrm{x})$ to decrease the $\mathrm{pH} \approx 8$. After washing and neutralizing the residues, the gel was dried at $\approx 80^{\circ} \mathrm{C}$ for $12 \mathrm{~h}$ in an electric oven ${ }^{27}$. After drying process the FUHT material was stored for further quantitative and qualitative analysis in addition to potential applications. Figure 1 shows high temperature conversion of RFA into value added GSZ materials by Alkaline Fusion (FUZ) and Fusion Assisted Hydrothermal process (FUHT).

\subsection{Characterization of RFA and GSZ}

Sorption behavior of RFA and GSZ was determined by Cation Exchange Capacity (CEC) measured in SI units as m.eq/100 g of sample. The CEC values were determined following the ammonium acetate procedure by ICARDA manual.

The crystallinity and mineralogical composition of RFA and synthetic products were recognized by powdered XRD analysis on a Bruker D8 instrument by subjecting to $\mathrm{Cu}-\mathrm{Ka}$ radiations. XRD data collection was conceded out via $2 \theta$ in the range of $10-50^{\circ}$, with a scanning ${ }^{28}$ step of $0.02^{\circ}$. FTIR (ATR) spectroscopy is helpful for getting information of zeolite like surface chemistry and functionality ${ }^{29}$. The samples were scanned in the range of 4000-450 $\mathrm{cm}^{-1}$ using Spectrum-2, FTIR spectrophotometer from Perkin Elmer in a transmission mode. Though, just $3500-500 \mathrm{~cm}^{-1}$ region was studied since, it is where the spectra showed major variations ${ }^{30}$. Morphology of the raw and zeolite materials was investigated by SEM on a JSM-5910 Scanning Electron Microscope by JEOL under following conditions: $\mathrm{EHT}=15.00 \mathrm{kV}$, Signal A $=$ SE1, $\mathrm{WD}=8.0 \mathrm{~mm}^{\underline{31}}$.

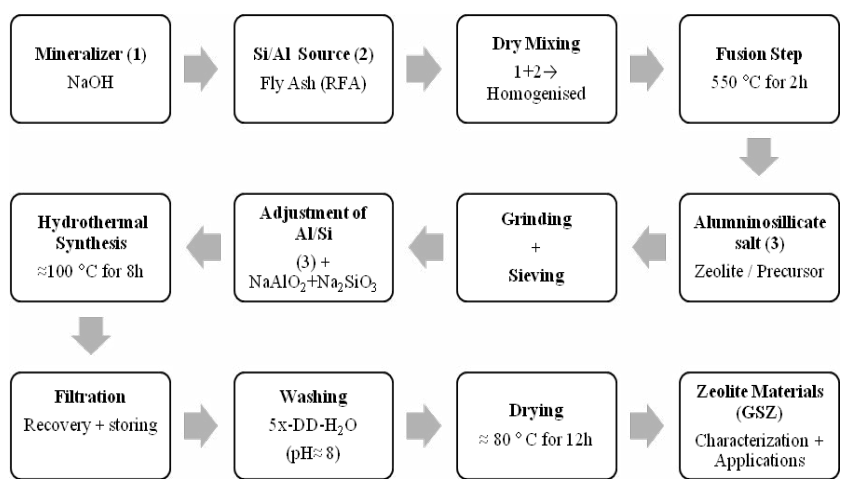

Figure 1. Alakline Fusion (FUZ) and Fusion Assisted Hydrothermal (FUHT) geopolymerization of RFA to GSZ.

\subsection{Heavy Metal Removal}

The sorption of metal ions onto RFA and zeolite was conducted to examine their effectiveness to decontaminate waste water. As (III) stock solution $(1000 \mathrm{mg} / \mathrm{L})$ was prepared by dissolving $\mathrm{As}_{2} \mathrm{O}_{3}$ in $\mathrm{DI}-\mathrm{H}_{2} \mathrm{O}$ while working solutions were made by further dilution. Sorption tests

Table 1. Treatment and physico-chemical properties of RFA, FUZ, FUHT

\begin{tabular}{|l|l|l|l|l|l|}
\hline Sample & Treatment & $\mathbf{p H}$ & EC $($ u $/$ /cm $)$ & LOI $\%$ & CEC $\mathbf{m . e q} / \mathbf{1 0 0 g}$ \\
\hline $\mathrm{DI} \mathrm{H}_{2} \mathrm{O}$ & N/A & 7.00 & 20 & N/A & 00 \\
\hline RFA & N/A & 8 & 70 & 3.2 & 73 \\
\hline FUZ & Alkaline Fusion & 11 & 254 & 0.01 & 230 \\
\hline FUHT & Fusion+Hydrothermal & 12 & 345 & 1.1 & 310 \\
\hline
\end{tabular}


were evaluated in $100 \mathrm{ml}$ Erlenmeyer flasks through batch type reactions at room temperature by using a given sorbent dose. The suspension was kept in an orbital shaker with a constant stirring speed of $300 \mathrm{rpm}$ for selected time range. In these experiments the sorbent:liquid ratio was varied to investigate the effects of variation of sorbent dose on the metal retention of As (III) with the sorbent. Similarly time and $\mathrm{pH}$ of the heterogeneous mixture were also optimized by batch experiments using a fixed amount of adsorbent for variable reaction times and $\mathrm{pH}$ range. After the programmed time, each reaction vessel was removed from the shaker and the supernatant collected by filtering the suspension were set aside in a refrigerator at $\approx 4^{\circ} \mathrm{C}$ for ICP-AES analysis via Prodigy 7-ICP-AES by Teledyne Leeman Labs. The quantity of arsenic adsorbed by different adsorbents $s^{32}$ is determined by using the following Equation (1).

$$
A c=V \frac{C o-C e}{m} e q .(1)
$$

Where, "Ac" is Arsenic (III) concentration (ug/g) adsorbed by the RFA, FUZ and FUHT at equilibrium, "Co" and "Ce" are concentrations of arsenic (ug/L) in solution before and after treatment respectively, whereas, " $\mathrm{m}$ " is mass (g) of adsorbents used and " $\mathrm{V}$ " is volume (L) of heterogeneous solution. The intact series of experiments carried in triplicate to assess test reproducibility under the same conditions.

\section{Results and Discussions}

\subsection{Physicochemical Characteristics of RFA and GSZ}

Extract of the RFA shows a little basic $\mathrm{pH}$ while the supernatants of the fused products show higher $\mathrm{pH}$ due to alkaline salt formation. Similarly for hydrothermal crystallization products produces highly basic supernatant due to addition of alkali and aluminosillicates in order to adjust the $\mathrm{Al} / \mathrm{Si}$ ratio. Electrical Conductivity (EC) measurement is a fast, inexpensive and reliable way of measuring the ionic content in a solution ${ }^{33}$. EC of the deionized water is extremely low and EC of RFA extract is not increased as much due to presence of insoluble components in water. On the other hand, addition of $\mathrm{NaOH}$ during fusion step involves the alkaline salt formation with great mobility of respective ions results in rise of conductance. Similarly during FUHT a number of electrolytes are augmented which amplified EC at high temperature where the solubility favors thermodynamically. Loss on ignition of RFA is related to the presence of carbonates, joint water in residual minerals and combustion of complimentary carbon. The result for RFA shows 3.2\% loss on ignition which emphasized F-type ash of low Ca contents as per (ASTM-C618) ${ }^{34}$. Carbon is the most important constituent of LOI which is encapsulated in glassy crystallites during incineration. Fusion products showed minimum LOI since resultant product is fused at high temperature where all the combustibles are lost. Increase in LOI of FUHT is linked to the moisture contents even after oven drying at $80^{\circ} \mathrm{C}$. Likewise, adsorbent materials are renowned by their central and valuable property, known as the Cation Exchange Capacity (CEC), which defines its suitability for diverse industrial and environmental applications in metal removal from aqueous medium.

During synthesis of sodium zeolites, several of the tetravalent $\mathrm{Si}$ atoms are replaced by the trivalent $\mathrm{Al}$ atoms hence creating a deficiency of a positive charge which is responsible for its Cation Exchange Capacity (CEC). This charge is balanced by $\mathrm{Na}^{+}$considering that it is openly linked to the presence of sodium zeolite materials. Actually, synthesized zeolites are mesoporous material which have high CEC and facilitate to entrap heavy metal ions in its porous structure. It is apparent from the results in Table 1, CEC of Raw Fly Ash (73) is very low while, the geopolymerized products enhanced by varying fusion (230) and hydrothermal (310) crystallization eventually useful in sequestration of As (III) from water.

\subsection{Alkaline Fusion followed by Hydrothermal Synthesis}

Calcinations approach was adopted in this study because sufficient amounts of aluminosilicates can be dissolved by using fusion method. A number of researchers have reported utmost values of $\mathrm{SiO}_{2} / \mathrm{Al}_{2} \mathrm{O}_{3}$ and extent of crystallinity at a fusion temperature of $550^{\circ} \mathrm{C}$ for 2 hours. The alkali $(\mathrm{NaOH})$ added to the starting raw material acts as an activating/mineralizing agent during fusion process. Zeolite yield from the fusion process can be as high as $\pm 95 \%$ because a number of the static crystalline phases in the RFA can be entirely reacted during calcinations step and if the percentage of unburnt carbon in Raw Fly Ash is least. In the alkaline fusion step, a solid-state reaction among the $\mathrm{NaOH}$ activator and the crystalline phases of 
RFA such as quartz $\left(\mathrm{SiO}_{2}\right)$ and mullite $\left(\mathrm{Al}_{2} \mathrm{O}_{3}+\mathrm{SiO}_{2}\right)$ are present. As a result, a good number of the RFA material particles were converted into sodium silicate and aluminate salts i.e. FUZ at the blending temperature $\left(550^{\circ} \mathrm{C}\right)$. An alkaline fusion step was engaged proceeding to the hydrothermal treatment, because it plays a significant role in augmenting the hydrothermal process for zeolite blending. These novel metrics dissolved in aqueous medium more readily than quartz and mullite in the preliminary RFA phase ${ }^{35}$.

\subsection{FTIR Analysis}

The FTIR (ATR) spectra of the RFA and GSZ obtained after Alkaline Fusion (FUZ) and Fusion Assisted Hydrothermal Treated (FUHT) materials are illustrated in Figure 2. The transmittance spectra of the GSZ products show remarkable differences when compared to the spectrum of the RFA. Synchronized with the progressive makeover of RFA, typical zeolitic bands of alluminosillcate are observed on the FTIR spectra. The bands in the region of $400-500 \mathrm{~cm}^{-1}$ are attributed to internal tetrahedron vibrations of $\mathrm{Si}-\mathrm{O}$ and $\mathrm{Al}-\mathrm{O}$ or (T-O bands) also termed as bending vibrations of $\mathrm{Si} / \mathrm{Al} /-\mathrm{O}$ bond of the zeolitic materials when a $\mathrm{NaOH}$ solution was used. The internal symmetric stretching vibration bands are present in the region of $720-650 \mathrm{~cm}^{-1}$ can be identified after RFA activation in concentrated alkaline solutions as observed at $712 \mathrm{~cm}^{-1}$ for alkaline activated product by FUHT. Using $\mathrm{NaOH}$ as mineralizer in the alkaline fusion method, variable frequencies are obtained where new bands at higher frequencies represent the external symmetric stretching vibrations in the region of $830-920 \mathrm{~cm}^{-1}$. External symmetric vibrations are presented as sharp peak at $874 \mathrm{~cm}^{-1}$ for alkaline fusion and at $878 \mathrm{~cm}^{-1}$ for FUHT products except RFA. Those vibration bands observed at 950-1250 $\mathrm{cm}^{-1}$ associated with internal asymmetric (T-O) stretching vibrations are shifted towards higher frequencies. Apparently, new bands of lower frequencies appeared at $959 \mathrm{~cm}^{-1}$ in fusion process. Similarly, external asymmetric vibrations are present in the range of $1030-1170 \mathrm{~cm}^{-1}$ whereas, bands at $1062 \mathrm{~cm}^{-1}, 1157 \mathrm{~cm}^{-1}$ and $1040 \mathrm{~cm}^{-1}$ linked to RFA, FUZ and FUHT treated products respectively. Conversely, two bands at $1425 \mathrm{~cm}^{-1}$ and $1430 \mathrm{~cm}^{-1}$ could be attributed to vibrations of the external hydroxyl groups linked to FUZ and FUHT treated product respectively ${ }^{36}$. The swing in absorption frequency is allied to compositional property directly linked to $\mathrm{Al} / \mathrm{Si}$ ratio and active zeolitization of RFA into value added GSZ ${ }^{37}$.

\subsection{SEM Micrographs}

Scanning Electron Microscope (SEM) images of RFA and the GSZ produced through fusion and fusion assisted hydrothermal techniques are illustrated in given Figure 3. RFA after crystallization and filtration produces GSZ with crystalline shapes such as rectangular and cubic geometries for Na-P1, mesoporous agglomerates reassembles $\mathrm{NaX}$ type sodium aluminosillicate. Micrographs obtained by SEM of the RFA and its GSZ have been found to be a useful tool for demonstrating the form, structures and grain size of constituent minerals. Similarly morphological composition was characterized principally by amorphous aluminosilicates, although mullite and quartz phases occur in unreacted glassy form ${ }^{38}$. After the geopolymerization process, the surface of RFA shows evident changes as alkaline fusion produces porous materials can mitigate the metallic ions from contaminated water through chemisorptions. While hydrothermal crystallization of fused salt decreases the crystallinity of $\mathrm{NaX}$ and converts into $\mathrm{NaP} 1$ type zeolite at ambient temperature for $8 \mathrm{~h}$ duration. The resultant geopolymer zeolites yet have the application as adsorbents to remove heavy metals i.e. As (III) from synthetic waste water.

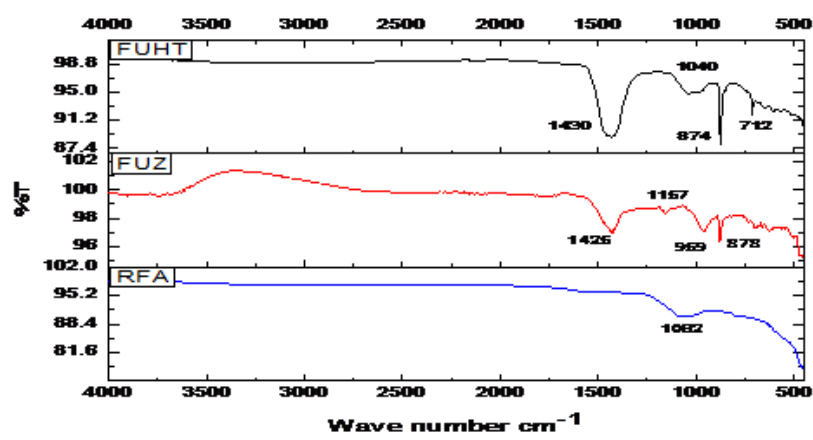

Figure 2. FTIR (ATR) spectra of RFA, FUZ and FUHT showing variation in functionality and surface chemistry.

\subsection{XRD Analysis}

The XRD results back up the success of both FUZ and FUHT synthesis techniques in RFA conversion into value added product i.e. GSZ. However, a comparison amid the two methods suggests the action of diverse mechanisms controlling the synthesis of the newly formed mineral phases ${ }^{39}$. X-ray Diffraction (XRD) analysis has been a useful tool to check the presence of minerals viz. mullite and quartz as the main crystalline phase in the RFA. Crystallograms show the mineralogical composition is dominated by the existence of amorphous as well as crys- 
talline aluminosilicates, although mullite and quartz also occur as glass material along with the main presence of sodium silicate $\left(\mathrm{Na}_{2} \mathrm{SiO}_{3}\right)$ and sodium aluminosilicate $\left(\mathrm{NaAlSiO}_{4}\right)$ as geopolymerized sodium zeolites. Figure 4 shows the presence of crystalline phases of quartz (Q), Mullite (M), $\mathrm{NaX}(\mathrm{X}), \mathrm{NaP} 1(\mathrm{P})$ and hydroxyl sodalite (S) were identified by structure commission of international zeolite association and Crystallography Open Database (COD) files. It is evident that crystalline phases of zeolites are developed by alkaline fusion with $\mathrm{NaOH}$ as compared to RFA where only quarts and mullite present as aluminates and silicates along with their mixture. Fusion synergized with hydrothermal treatment is superior as compared to single mode fusion technique showing $\mathrm{NaX}$ and SOD with un-reacted glassy phases. Figure 4, justifies the comparable FUHT method polymerizes solid waste ash (RFA) to NaP1 zeolite under prolong time of crystallization.

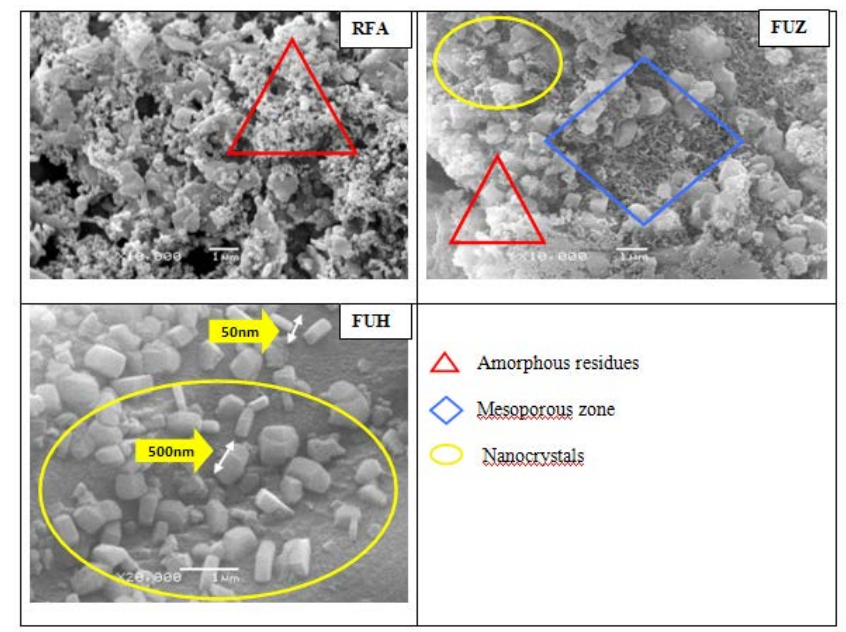

Figure 3. Micrographs of RFA, FUZ and FUHT aluminosillicate zeolite showing amorphous and crystalline morphology after geopolymerization ranging from 50 to 500 $\mathrm{nm}$.

\subsection{Heavy Metal Removal}

\subsubsection{Effect of $p H$ and Adsorbent Dose on Sequestration of As (III) Ions}

Preliminary, the effect of $\mathrm{pH}$ on heavy metal adsorption by RFA and GSZ was investigated at 1 to $11 \mathrm{pH}$ by using $(0.1$ M) $\mathrm{NaOH}$ and $\mathrm{HCl}$. It is visible from Figure 5 that with the increase in $\mathrm{pH}$ of the heterogeneous solution the residual arsenic concentration decreases and reached a minimum at $\mathrm{pH} \approx 8$. Later on as the $\mathrm{pH}$ is increased from 8 to 11 arsenic concentrations also increases slightly showing steady adsorption behavior of adsorbents by their mesoporous characteristics. This confirms that, a $\mathrm{pH} \approx 8$ is considered to be suitable for efficient removal of heavy metal ions. Quite a few researchers like $\frac{40-42}{2}$, also found that $\mathrm{pH}$ close to 8 is suitable for As (III) ions removal. With the increase in $\mathrm{pH}$, negatively charged species of arsenic are augmented as compared to positive and for successful sequestration of As (III), the $\mathrm{pH}$ of solution ${ }^{43}$ should be over 7 . The effect of adsorbent dose on arsenic adsorption was investigated for 50 to $300 \mathrm{mg} /$ solution range. The experiments were conducted using $50 \mathrm{~mL}$ solution of lowest $100 \mathrm{ug} / \mathrm{L}$ arsenic at $\mathrm{pH} \approx 8$ for 30 minutes of batch reaction time. Varying doses of RFA and Geopolymerized Sodium Zeolites (GSZ) were mixed with polluted solution, the results reveal that with increase in zeolite dose the residual arsenic concentration decreases up to $150 \mathrm{mg} / \mathrm{L}$ dose of adsorbent after which the decline in arsenic is almost insignificant. For that reason, for next trials initial $\mathrm{pH}$ was set to $\approx 8$ and dose of adsorbent was fixed as $150 \mathrm{mg} / \mathrm{L}$.

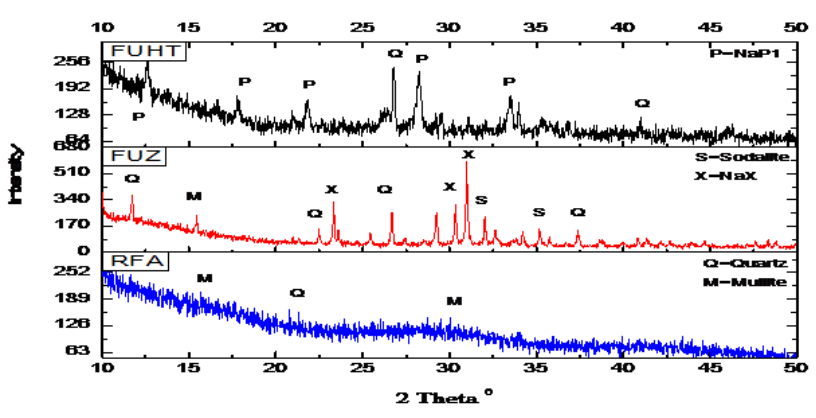

Figure 4. X-rays spectra of RFA, FUZ and FUHT aluminosillicate zeolite showing amorphous and crystalline phases after geopolymerization showing vriety of sodium zeolites.

\subsubsection{Effect of Initial Arsenic Concentration on RFA and GSZ for As (III) Sequestration}

The effect of initial arsenic concentration was studied on Raw Fly Ash (RFA) and Geopolymerized Sodium Zeolites (GSZ) for removal of As (III). The experiments were conducted at fixed parameters like; $\mathrm{pH} \approx 8,150 \mathrm{mg} / \mathrm{L}$ of adsorbent and reaction time range of 10-60 minutes. The samples were collected in a gap of 10 minutes and it is observed that at a fixed reaction time for all the adsorbents, an increased value of initial As (III) concentration increases the residual arsenic quantity. Most of the As (III) 
ions present in the mixture interacts with the active sites of the adsorbents facilitating adsorption for $100 \mathrm{ug} / \mathrm{L}$. It can be experiential from the bar graph Figure 6, that for $100 \mathrm{ug} / \mathrm{L}$ initial metal ion concentration and 30 minutes of reaction time the residual arsenic concentration for RFA = $64 \mathrm{ug} / \mathrm{L}, \mathrm{FUZ}=22 \mathrm{ug} / \mathrm{L}$ and for FUHT it was just $10 \mathrm{ug} / \mathrm{L}$. Hence, it shows that FUHT is a better adsorbent for heavy metal removal ( $\pm 90 \%$ removal in $30 \mathrm{~min}$ ), especially for As (III) when compared with RFA and FUZ. FUHT was capable to decrease the arsenic concentration well within the permissible range by $\mathrm{WHO}(<10-15 \mathrm{ug} / \mathrm{L})$. It is also evident from the Figure 6 that at fixed time of 30 minutes the residual arsenic increases from $10-24 \mathrm{ug} / \mathrm{L}$ as the original arsenic concentration is increased in mixture as 100,200 and $300 \mathrm{ug} / \mathrm{L}$ for FUHT adsorbent. Similarly, for constant 90 minutes duration of reaction, residual arsenic concentration changes from 8-15 ug/L. It is because at lower concentrations of metal ions, majority of the As (III) present in heterogeneous solution interact with the active sites of adsorbents facilitate in elevated adsorption ${ }^{44}$.
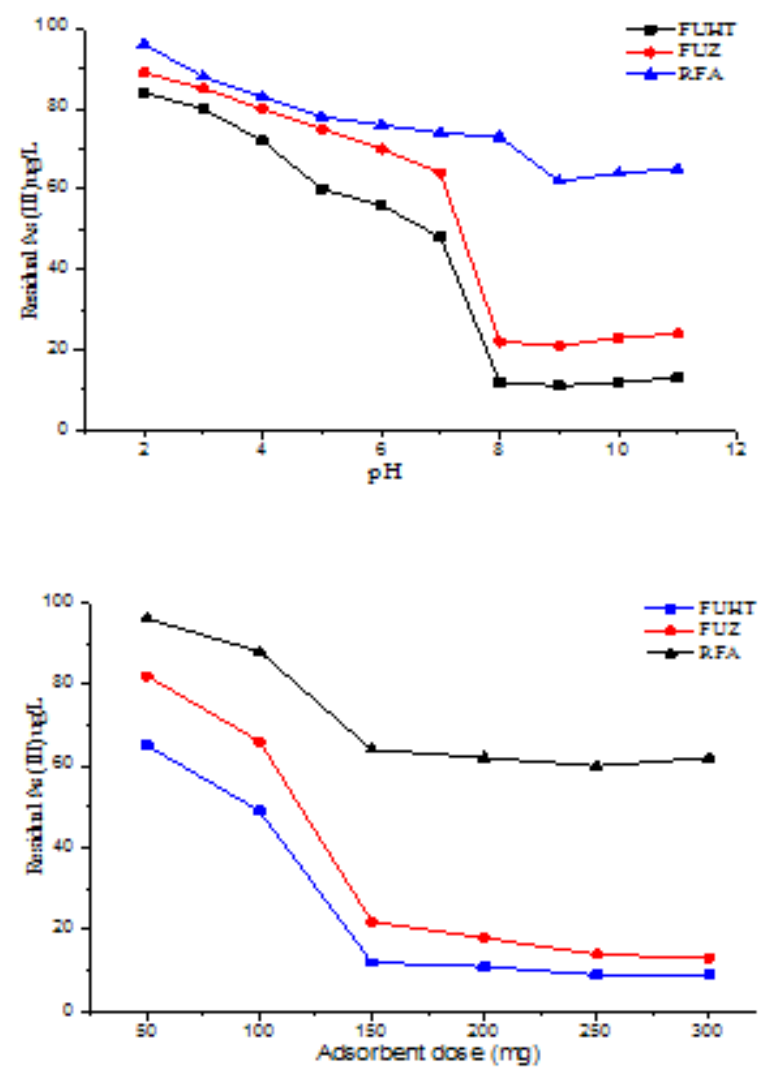

Figure 5. Effect of $\mathrm{pH}$ and dose of adsorbents on sequestration of As (III) by using RFA, FUZ and FUHT for 30 minutes of batch reaction.

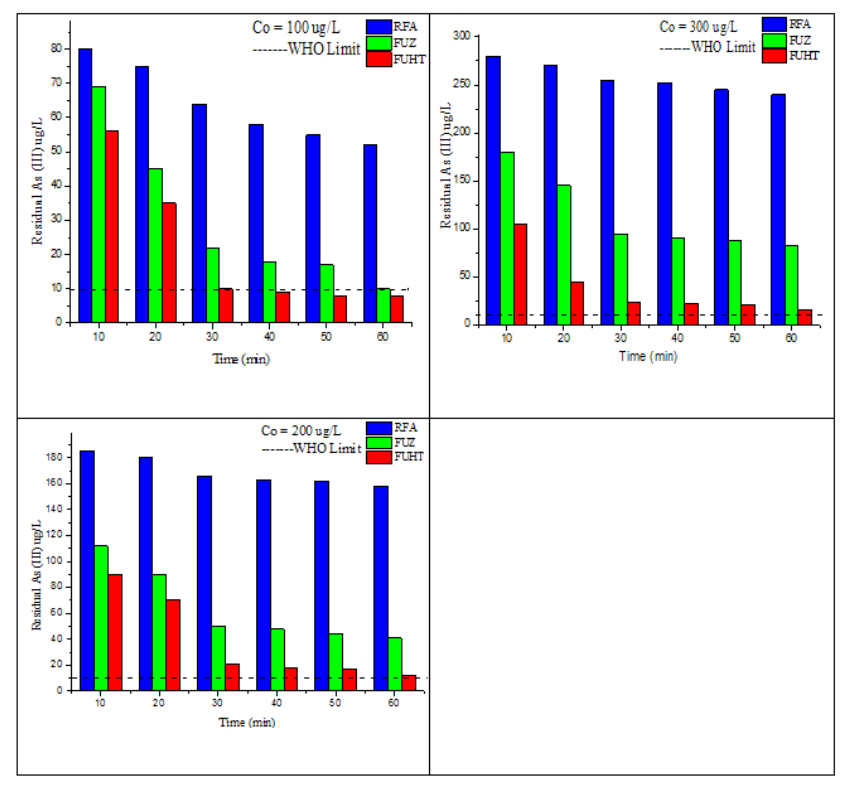

Figure 6. Effects of change in original concentration (Co) of AS (III) on its adsorption by using RFA and GSZ for varying time domain in batch reactions via keeping $\mathrm{pH} \approx 8$ and 150 $\mathrm{mg}$ fixed dose of geopolymerized adsorbents.

\subsubsection{Effect of Time on Adsorption Capacity of As (III) by RFA and GSZ}

Further analysis of results, a line graph Figure 7, was plotted for RFA and GSZ between Adsorption capacity (Ac) and time. It was observed that adsorption capacity of RFA increases from 12 to $21 \mathrm{ug} / \mathrm{g}$, in case of FUZ adsorbent it changes from 47 to $136 \mathrm{ug} / \mathrm{g}$ and for FUHT products Adsorption capacity (Ac) varies from 68 to $148 \mathrm{ug} / \mathrm{g}$ for optimum time of 30 minutes when initial arsenic concentration is assorted as $100 \mathrm{ug} / \mathrm{L}, 200 \mathrm{ug} / \mathrm{L}$ and $300 \mathrm{ug} / \mathrm{L}$.

Correspondingly, at maximum time duration for 60 minutes of batch reaction Adsorption capacity (Ac) for RFA changes from 14 to $21 \mathrm{ug} / \mathrm{g}$, for FUZ it ranges from 55 to 150 and in case of FUHT it increases from 74 to 150 $\mathrm{ug} / \mathrm{g}$ by varying As (III) working solution concentrations. The results show that with the rise in concentration of As (III) ions in solution, additional ions are accessible for adsorption consequently escalating the adsorption performance of materials. At elevated concentrations, several favorable active sites are involved ${ }^{45}$ conversely; sorption process reaches to logged point where the limited active sites on the adsorbent are covered completely by the adsorbate. The As (III) adsorption on GSZ is the result of exchange between terminal hydroxyl groups of aluminates and silicates along with adsorbate anionic species. 
The mechanism of As (III) chemisorption on FUZ and hydrothermally treated Fused Zeolite FUHT based composites can be interpreted as surface complex modeling ${ }^{46}$.

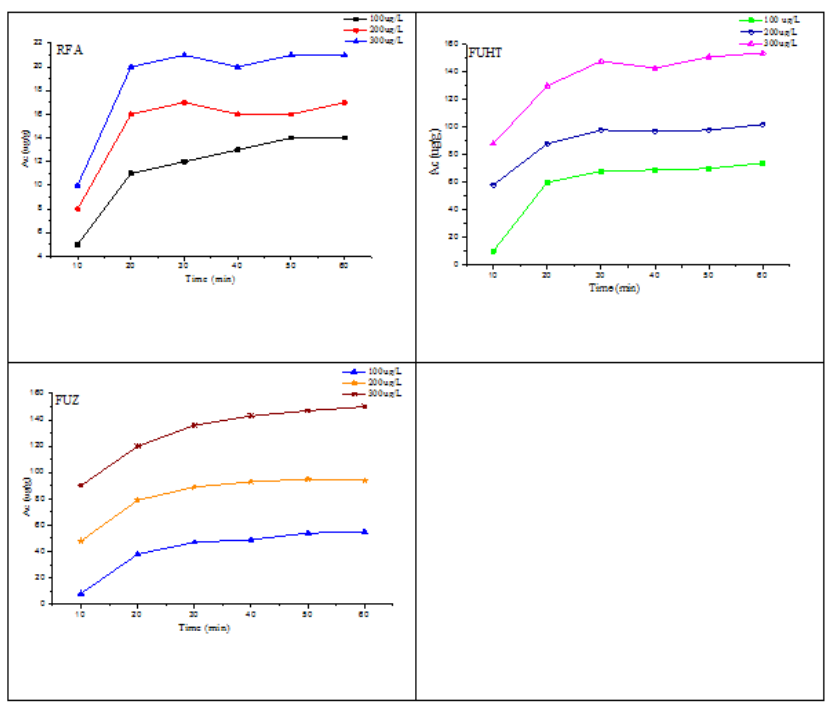

Figure 7. Effects of time variation on adsorption capacity of As (III) by RFA, FUZ and FUHT for varying initial concentration of metal ion i.e. $100,200,300 \mathrm{\otimes g} / \mathrm{L}$ in batch reactions by keeping $\mathrm{pH} \approx 8$ and $150 \mathrm{mg} / \mathrm{L}$ fixed dose of geoplymerized adsorbent.

\subsection{Adsorption Isotherms}

FUHT treated sodium zeolite showed the excellent activity as an adsorbent in this work and was able to cut the residual As (III) concentration below the WHO standards. Therefore, the adsorption isotherm study was performed for the activity data of FUHT material. The experimental data was fitted in the Langmuir and Freundlich adsorption isotherm for homo and heterogeneous equilibrium respectively. Langmuir isotherm explains homogeneous monolayer adsorption, with no trans-movement of the adsorbate in the plane of the adsorbent surface. Freundlich isotherm is non-ideal and useful to predict reversible heterogeneous adsorption mechanism for multilayer deposition ${ }^{47}$. Adsorption of As (III) by FUHT as a function of time for taking variable arsenic concentration $(100,200,300)$ shows surface adsorption is the rate-limiting step that involves chemi-sorption, where the removal from a solution is due to physico-chemical interactions between adsorbent and adsorbate phases ${ }^{48}$. The results are fitted by Langmuir and Freundlich isotherms, accordingly it can be concluded that adsorption of arsenic to sodium zeolite is hybrid mechanism and does not practice ultimate monolayer adsorption process.

\section{Conclusions}

A solid industrial waste (RFA) was successfully geopolymerized into value added sodium zeolite GSZ (i.e. NaX, SOD, NaP1) by synergic method and resultant composites are effective for As (III) removal in aqueous medium. Results showed that, FUHT zeolite is best mesoporous adsorbent to uptake toxic As (III) in comparison to RFA or other adsorbents. FUHT zeolite shows $\pm 90 \%$ removal efficiency within 30 minutes at $\approx 8 \mathrm{pH}$ and able to reduce arsenic concentration well within WHO limits economically. Adsorption isotherm suitably described by both Langmuir and Freundlich isotherm models that indicate that the reaction between Na-Zeolites and As (III) in heterogeneous solution is a hybrid mechanism and not monolayer surface phenomena. Novel modification of solid waste into zeolite and their effective performance in heavy metal sequestration from water should be amenable to solid waste management and water purification.

\section{References}

1. United States Environmental Protection Agency. 1997. https://www.epa.gov/

2. Lim SR, Schoenung JM. Human health and ecological toxicity potentials due to heavy metal content in waste electronic devices with flat panel displays. Journal of Hazardous Materials. 2010; 177:251-9. PMid: 20056318. https://doi. org/10.1016/j.jhazmat.2009.12.025

3. Mukesh KR, Kumar P, Singh M, Singh A. Toxic effect of heavy metals in livestock health. Veterin World. 2008; 1:2830. https://doi.org/10.5455/vetworld.2008.28-30

4. Khalil HPSA, Yusra AFI, Bhat AH, Jawaid M. Cell wall ultrastructure, anatomy, lignin distribution and chemical composition of Malaysian cultivated kenaffiber. Industrial Crops and Products. 2010; 31:113-21. https://doi. org/10.1016/j.indcrop.2009.09.008

5. Barbieri L, Bonamartini AC, Lancellotti I. Alkaline and alkaline-earth silicate glasses and glass-ceramics from municipal and industrial wastes. Journal of the European Ceramic Society. 2000; 20:2477-83. https://doi.org/10.1016/ S0955-2219(00)00124-2

6. LiuB, WangD, LiH, XuY,ZhangL.As(III)removalfromaqueous solution using $\alpha-\mathrm{Fe}_{2} \mathrm{O}_{3}$ impregnated chitosan beads with As (III) as imprinted ions. Desalination. 2011; 272:286-92. https://doi.org/10.1016/j.desal.2011.01.034

7. Pereira FV, Gurgel LVA, Gil LF. Removal of Zn2p from aqueous single metal solutions and electroplating wastewater with wood sawdust and sugarcane bagasse modified with EDTA di-Anhydride (EDTAD). Journal of 
Hazardous Materials. 2010; 176:856-63. PMid: 20047793 https://doi.org/10.1016/j.jhazmat.2009.11.115

8. Rawat M, Ramanathan AL, Subramanian V. Quantification and distribution of heavy metals from small scale industrial areas of Kanpur City, India. Journal of Hazardous Materials. 2009; 172:1145-9. PMid: 19699581. https://doi. org/10.1016/j.jhazmat.2009.07.115

9. Sud D, Mahajan G, Kaur MP. Agricultural waste material as potential adsorbent for sequestering heavy metal ions from aqueous solutions. Bioresource Technology. 2008; 99:6017-27. PMid: 18280151. https://doi.org/10.1016/j. biortech.2007.11.064

10. Mondal P, Bhowmick S, Chatterjee D, Figoli A, Van der Bruggen B. Remediation of inorganic arsenic in groundwater for safe water supply: A critical assessment of technological solutions. Chemosphere. 2013; 92:157-70. PMid: 23466274. https://doi.org/10.1016/j.chemosphere.2013.01.097

11. Nabi SA, Akhtar A, Khan MDA, Khan MA. Synthesis, characterization and electrical conductivity of polyaniline-Sn (IV) tungstophosphate hybrid cation exchanger: Analytical application for removal of heavy metal ions from wastewater. Desalination. 2014; 340:73-83. https:// doi.org/10.1016/j.desal.2014.02.020

12. Shahadat M, Teng TT, Rafatullah M, Arshad M. Titanium based nanocomposite materials: A review of recent advances and perspectives. Colloids and Surfaces B: Biointerfaces. 2015; 126:121-37. PMid: 25543989. https:// doi.org/10.1016/j.colsurfb.2014.11.049

13. Ahmad R, Kumar R, Haseeb S. Adsorption of $\mathrm{Cu}^{2+}$ from aqueous solution onto iron oxide coated eggshell powder: Evaluation of equilibrium, isotherms, kinetics and regeneration capacity. Arabian Journal of Chemistry. 2012; 5:353-9. https://doi.org/10.1016/j.arabjc.2010.09.003

14. Kurniawan TA, Chan GYS, Hung LW, Babel S. Physicochemical treatment techniques for wastewater laden with heavy metals. Chemical Engineering Journal. 2006; 118:8398. https://doi.org/10.1016/j.cej.2006.01.015

15. Shahadat M, Nabi SA, Bushra R, Raeissi AS, Umar K, Ansari MO. Synthesis, characterization, photolytic degradation, electrical conductivity and applications of nanocomposite adsorbent for the treatment of pollutants. RSC Advances. 2012; 2:7207-20. https://doi.org/10.1039/c2ra20589k

16. Khan AA, Innamuddin. Application of $\mathrm{Hg}(\mathrm{II})$ sensitive polyaniline Sn (IV) phosphate composite cation exchange material in determination of $\mathrm{Hg}^{2+}$ from aqueous solutions and in making ion selective membrane electrode. Sensors and Actuators B: Chemical. 2006; 120:10-8. https://doi. org/10.1016/j.snb.2006.01.033

17. Raman NK, Anderson MT, Brinker CJ. Template based approaches to the preparation of amorphous, nanopo- rous silicas. Chem Mater. 1996; 8:1682-701. https://doi. org/10.1021/cm960138+

18. Querol X, Moreno N, Alastuey A, Juan R, Andres JM, Lopez-Soler A, Ayora C, Medinaceli A, Valero A. Synthesis of high ion exchange zeolite from coal fly ash. Geologica Acta. 2007; 5(1):49-57.

19. Rege SU, Yang RT. Limits for air separation by adsorption with LiX zeolite. Industrial and Engineering Chemistry Research. 1997; 36:5358-65. https://doi.org/10.1021/ ie9705214

20. Eken-Saracoglu N, Culfaz M. Clinoptilolite zeolite as a builder in nonphosphated detergents. Journal of Environmental Science and Health, Part A. 1999; 34:161926. https://doi.org/10.1080/10934529909376916

21. Li Z, Jean JS, Jiang WT, Chang PH, Chen CJ, Liao L. Removal of arsenic from water using $\mathrm{Fe}$-exchanged natural zeolite. Journal of Hazardous Materials. 2011; 187:318-23. PMid: 21315510. https://doi.org/10.1016/j.jhazmat.2011.01.030

22. Siska J. Extraction of heavy metals and ammonium from waters by unsaturated fatty acids and their soaps. Hydrometallurgy. 2005; 76:155-72. https://doi. org/10.1016/j.hydromet.2004.09.001

23. Ojha K, Pradhan NC, Samanta AN. Zeolite from fly ash: Synthesis and characterization. Bulletin of Materials Science. 2004; 27(6):555-64. https://doi.org/10.1007/ BF02707285

24. Shaobin W, Zhu ZH. Sonochemical treatment of fly ash for dye removal from wastewater. Journal of Hazardous Materials. 2005; 126:91-5. PMid: 16046059. https://doi. org/10.1016/j.jhazmat.2005.06.009

25. Inada $M$, Tsujimoto $H$, Eguchi $Y$, Enomoto $N$, Hojo J. Microwave-assisted zeolite synthesis from coal fly ash in hydrothermal process. Fuel. 2005; 84:1482-6. https://doi. org/10.1016/j.fuel.2005.02.002

26. Fly ash zeolites innovations, applications and directions. 2016. https://www.springer.com/gp/book/9789811014024

27. Belviso C, Cavalcante F, Lettino A, Fiore A. Effects of ultrasonic treatment on zeolite synthesized from coal fly ash. Ultrasonics Sonochemistry. 2011; 18:661-8. PMid: 20851662. https://doi.org/10.1016/j.ultsonch.2010.08.011

28. Collection of Simulated XRD Powder Patterns for Zeolites. 2001. http://www.iza-structure.org/books/Collection_4ed.pdf

29. Zeolite Characterization and Catalysis: A tutorial. 2009. https://www.springer.com/gp/book/9781402096778

30. Somerset VS, Petrik LF, White LR, Klnka MJ, Key D, Iwuoha EI. Alkaline hydrothermal zeolites synthesized from high $\mathrm{SiO}_{2}$ and $\mathrm{Al}_{2} \mathrm{O}_{3}$ co-disposal fly ash filtrates. Fuel. 2005; 84:2324-9. https://doi.org/10.1016/j.fuel.2005.05.012

31. Williams DB. Practical analytical electron microscopy in materials science. British Polymer Journal. 1986; 18(1):678. https://doi.org/10.1002/pi.4980180121 
32. Soni R, Shukla DP. Data on Arsenic (III) removal using zeolite-reduced graphene oxide composite. Data in Brief. 2019; 22:871-7. PMid: 30723756 PMCid: PMC6352290. https:// doi.org/10.1016/j.dib.2019.01.004

33. Conductivity analyzers and their application. 2004. https:// onlinelibrary.wiley.com/doi/10.1002/0471473332.ch23

34. ASTM C618 standard specification for coal fly ash and raw or calcined natural pozzolan for use in concrete. 2019. https://www.astm.org/Standards/C618.htm

35. Synthesis of zeolites from geological materials and industrial wastes for potential application in environmental problems. 2008. https://wlv.openrepository.com/handle/2436/39855

36. Gordina NE, Prokof'ev VY, Kul'pina YN, Petuhova NV, Gazahova SI, Hmylova OE. Effect of ultrasound on the synthesis of low-modulus zeolites from a metakaolin. Ultrasonics Sonochemistry. 2016; 33:210-9. PMid: 27245972. https://doi.org/10.1016/j.ultsonch.2016.05.008

37. Sitarz M, Mozgawa W, Handke M. Rings in the structure of silicate glasses. Journal of Molecular Structure. 1999; 281:511-2. https://doi.org/10.1016/S00222860(99)00169-6

38. Bukhari SS, Behin J, Kazemian H, Rohani S. Conversion of coal fly ash to zeolite utilizing microwave and ultrasound energies. A review. Fuel. 2015; 140:250-66. https://doi. org/10.1016/j.fuel.2014.09.077

39. Belviso C. Ultrasonic vs. hydrothermal method: Different approaches to convert fly ash into zeolite. How they affect the stability of synthetic products over time? Ultrasonics Sonochemistry. 2018; 43:9-14. PMid: 29555292. https:// doi.org/10.1016/j.ultsonch.2017.12.050

40. Soni R, Shukla DP. Synthesis of fly ash based zeolitereduced graphene oxide composite and its evaluation as an adsorbent for arsenic removal. Chemosphere. 2019; 219:504-9. PMid: 30553210. https://doi.org/10.1016/j.chemosphere.2018.11.203
41. Suzuki TM, Bomani JO, Matsunaga H, Yokoyama T. Preparation of porous resin loaded with crystalline hydrous zirconium oxide and its application to the removal of arsenic. Reactive and Functional Polymers. 2000; 43:165-72. https://doi.org/10.1016/S1381-5148(99)00038-3

42. Lenoble V, Laclautre C, Deluchat V, Serpaud B, Bollinger JC. Arsenic removal by adsorption on iron (III) phosphate. Journal of Hazardous Materials. 2005; 123:262-8. PMid: 15905023. https://doi.org/10.1016/j.jhazmat.2005.04.005

43. Katsoyiannis IA, Zouboulis AI. Removal of arsenic from contaminated water sources by sorption onto ironoxide-coated polymeric materials. Water Research. 2002; 36:5141-55. https://doi.org/10.1016/S00431354(02)00236-1

44. Chutia P, Kato S, Kojima T, Satokawa S. Arsenic adsorption from aqueous solution on synthetic zeolites. Journal of Hazardous Materials. 2009; 162:440-7. PMid: 18583035. https://doi.org/10.1016/j.jhazmat.2008.05.061

45. Baskan MB, Pala A. Removal of arsenic from drinking water using modified natural zeolite. Desalination. 2011; 281:396-403. https://doi.org/10.1016/j.desal.2011.08.015

46. Yang X, Xia L, Song S. Arsenic adsorption from water using graphene-based materials as adsorbents: A critical review. Surface Review and Letters. 2017; 24(4):1-12. https://doi. org/10.1142/S0218625X17300015

47. Foo K, Hameed B. Insights into the modeling of adsorption isotherm systems. Chemical Engineering Journal. 2010; 156:2-10. https://doi.org/10.1016/j.cej.2009.09.013

48. Wang H, Zhou A, Peng F, Yu H, Yang J. Mechanism study on adsorption of acidified multiwalled carbon nanotubes to $\mathrm{Pb}$ (II). Journal of Colloid and Interface Science. 2007; 316:277-83. PMid: 17868683. https://doi.org/10.1016/j. jcis.2007.07.075 